\title{
INFORMAÇÃO PROFISSIONAL E ORIENTAÇÃO PARA A CARREIRA MEDIADAS POR COMPUTADOR:UMA REVISÃO DA LITERATURA ${ }^{1}$
}

\author{
Marystella Carvalho Esbrogeo \\ Lucy Leal Melo-Silva
}

Resumo: A Informação Profissional, um dos componentes do processo de Orientação Profissional Vocacional ou para a Carreira, visa fornecer dados da realidade do mundo ocupacional de forma a auxiliar pessoas em processos de tomada de decisão. Este estudo objetiva sistematizar e analisar a produção do conhecimento sobre a temática Informação Profissional com base na revisão da literatura. Os dados foram organizados em três categorias, com base em Robinson e colaboradores: (1) modelos de recursos impressos, (2) programas e sistemas de informação e (3) sites na internet. Os resultados mostram que as novas Tecnologias da Informação e Comunicação (TICs) aliadas às estratégias tradicionais representam inúmeras oportunidades de desenvolvimento da Informação Profissional, com desafios e limites a serem enfrentados em um campo que não para de evoluir. O estudo evidencia o papel da Informação Profissional, com seus limites e possibilidades, no contexto brasileiro bem como nos países desenvolvidos.

Palavras-chave: Orientação profissional. Orientação vocacional. Orientação de carreira. Informação profissional. Sistemas de informação.

1 Este estudo é derivado da dissertação de mestrado da primeira autora com orientação da segunda. 


\section{Introdução}

A Orientação Vocacional, Profissional ou de Carreira, como a área é denominada no Brasil, pode ser definida como "qualquer estratégia concebida para ajudar um cliente a tomar e implementar decisões eficazes de carreira" (Spokane, 2004, p. 459). No Brasil e em outros países esse domínio do conhecimento teórico e prático se desdobra em grande diversidade de possibilidades de intervenção, tanto no que se refere aos referenciais teórico-metodológicos quanto no que se refere ao nível de aprofundamento da "Intervenção de Carreira", conceito utilizado internacionalmente (Melo-Silva, 2011).

A Informação Profissional, objeto deste estudo, pode ser considerada um componente muito importante da Orientação Profissional, como já afirmava Ferretti (1988), no contexto brasileiro, ou pode ser considerado um nível da intervenção de carreira, de acordo com Spokane (2004). Esse autor apresenta cinco níveis de intervenção de carreira, sendo o primeiro denominado informação, no qual se faz uso de folhetos e vídeos sobre profissões e cursos.

Feitas tais considerações, focaliza-se a questão da Informação Profissional para a escolha de carreira no contexto dos processos de Orientação Profissional com adolescentes no Brasil. O presente estudo está circunscrito à etapa da exploração na adolescência, fase em que é fundamental a busca de Informação Profissional para que a pessoa implemente sua escolha de carreira. Assim, como sugere Taveira (2000):

\footnotetext{
o significado da expressão "informação profissional" altera-se e passa a designar muitas das vezes o tipo de conteúdos envolvidos nos processos de exploração e de tomada de decisão. Por sua vez, escolhe-se o termo "exploração" para denominar os processos de procura, de interpretação e de integração de informação (pessoal e do mundo profissional) na resolução de problemas ou dilemas vocacionais. (p. 169)
}

Quando o jovem está pronto para tomar uma decisão de carreira? Segundo Savickas (2001), quando ele tem um vasto conhecimento baseado em informações e uma ampla exploração que facilite sua escolha. Assim, a informação sobre as profissões ocupa papel central nas intervenções de carreira e durante muito tempo foi quase a única prática de orientação educativa. Ela é empregada no processo de Orientação Profissional e de Carreira para ampliar o conhecimento sobre as profissões, corrigir as distorções e idealizações das profissões, criar estratégias de ação e conhecer as oportunidades e limitações no mercado de trabalho, além de sugerir objetivos e clarificar os caminhos para atingi-los. Na perspectiva educativa, pode modificar as representações que o sujeito pode 
ter do mundo do trabalho, enriquecendo-as, corrigindo-as e reestruturando-as (Guichard \& Huteau, 2001).

Há mais de 40 anos Kunze (1967, citado por Brown, 2003, p. 194) descrevia um modelo de informação ocupacional que minimamente revisado continua relevante nos dias de hoje. O modelo inclui (a) material impresso (livros, guias, informativos sobre carreiras e mercado de trabaIho, reportagens), (b) materiais programados, (c) materiais audiovisuais, como filmes e vídeos, (d) programas de multimídia que contêm componentes interativos, videoclipes e gráficos, (e) publicações armazenadas on-line, (f) simulação de situações reais de trabalho utilizando CD-ROM e o role play, (g) jogos, (h) Laboratório Ocupacional, (i) entrevistas com trabalhadores, (j) observação direta através de visitas ao local de trabalho, (k) experiências de exploração direta em amostra do trabalho, (I) experiências de estágios em período temporário e $(\mathrm{m})$ sites.

Os diferentes tipos de Informação Profissional, mencionados anteriormente, têm seus pontos favoráveis e desfavoráveis, principalmente ao se considerar alguns critérios importantes no momento de se optar por algum deles, a saber: a viabilidade do custo dos materiais, o envolvimento do orientando quando se utilizam instrumentos e a acessibilidade aos materiais (Brown, 2003).

Segundo Niles (1997), a informação de carreira ${ }^{2}$ pode ajudar os clientes a tomar decisões, entretanto, os orientadores devem se certificar de que as mesmas sejam precisas, relevantes e recentes, de modo a aumentar a probabilidade dos clientes obterem informação adequada sobre as carreiras, encorajando-os a usar fontes múltiplas de informação. Como salienta Brown (2003), cada jovem tem necessidades únicas.

Assim, como mencionado anteriormente, a Informação Profissional como um dos componentes (ou níveis) do processo de Orientação Profissional tem como objetivo básico fornecer dados que auxiliam a tomada de decisão. Esses dados se dividem em dois conjuntos: o primeiro a respeito das informações profissionais e o segundo a respeito do próprio indivíduo que escolhe (autoconhecimento). Este estudo focaliza o primeiro conjunto de informações, uma vez que os conflitos e problemas na escolha de carreira acontecem muitas vezes por ausência de informações.

Para Bohoslavsky (1991), as falhas na transmissão e/ou recepção da informação podem ser de ordem intrapessoal (características pessoais), interpessoal (dificuldades na identificação com pessoas/profissões) e transpessoal ou cultural (a valorização de algumas profissões em uma comunidade, com atribuição de poder, status).

20 termo "Informação Profissional" é distinto de "Informação de Carreira". Ao longo do texto "Informação de Carreira" é utilizado em citações de referências estrangeiras, objetivando ser fiel à tradução. Porém, em alguns momentos, os dois termos expressam o mesmo sentido. 
Ao salientar a necessidade da informação no processo de escolha da carreira, devem-se considerar os fatores econômicos, políticos e sociais que interferem nas possibilidades de escolha,"sem minimizar a complexidade da decisão enquanto fenômeno social", como aponta Ferretti (1988, p. 56).Ainda que as referências a Bohoslavsky (1991) e Ferretti (1988) datem de épocas anteriores ao advento intenso da internet e das TICs, elas permanecem válidas no sentido de destacar a importância cada vez maior da qualidade e fidedignidade da informação profissional, na época atual marcada pela efemeridade.

À medida que o jovem prossegue na escolha da sua carreira, questões específicas e pessoais emergem e precisam ser tratadas de maneira individualizada nos seus conteúdos. Guichard e Huteau (2001) perguntam:“Como fazer a escolha? Quais são os traços salientes de uma formação ou de uma profissão? É verdade que o orientador deve ser bem informado, mas ele corre sempre o risco de dar informações aproximativas ou enviesadas" (Guichard \& Huteau, 2001, p. 329). Segundo Ferretti (1988), desde o final do século passado, a Informação Profissional, quando empregada adequadamente no processo de Orientação Profissional, promovia a

ampliação do conhecimento sobre as profissões existentes e suas especializações; ampliação do conhecimento sobre as alternativas de ação, bem como a redução da gama dessas alternativas; correção de distorções nas imagens das profissões; desenvolvimento de expectativas mais realistas; consciência da necessidade de utilização de informações válidas e fidedignas nas escoIhas; maior conhecimento das oportunidades locais de trabalho. (Ferretti, 1988, p. 54)

A Informação Profissional também foi e é considerada importante no contexto da educação profissional, sendo definida como:"componente do processo de formação profissional, mediante o qual se fornecem esclarecimentos e orientações sobre o universo e as características do campo profissional, quanto às condições reais do mercado de trabalho local e suas tendências" (Brasil, 1981, p. 28). Assim, este estudo objetiva sistematizar e analisar a produção do conhecimento sobre Informação Profissional com base na revisão da literatura a partir da década de 1960.

\section{Procedimentos metodológicos e resultados}

O percurso metodológico consistiu em um levantamento preliminar de estudos realizados no período de 1962 a 2008 que tratam da Informação Profissional destinada aos adolescentes. As pesquisas tratadas nesse estudo foram selecionadas dos levantamentos realizados no PsycINFO, disponível em http://www.portaldapesquisa.com.br, no perío- 
do de 1962 a 2008, por meio da palavra-chave informação profissional (career information). Foram obtidas 397 referências e selecionados 18 artigos, que explicitamente tratavam da Informação Profissional, objeto do presente estudo. Além do referido material também foi consultada uma revista da área, mas disponível on-line, e quatro livros, considerados relevantes pelos autores, uma vez que abordam a Informação Profissional e auxiliaram na organização e análise dos dados.

Uma dificuldade encontrada no levantamento de dados para este estudo refere-se à palavra-chave informação profissional que tem seu sentido amplo e estendido para os mais diversos campos profissionais, por exemplo, orientação específica a uma dada carreira. Assim, definiu-se como critério de inclusão no material para análise a informação que visa propiciar insumos para adolescentes tomarem decisões de carreira. $\mathrm{O}$ corpus de análise, constituído por publicações nacionais e internacionais, encontra-se na Tabela 1 e na Tabela 2.

Tabela 1

Distribuição dos estudos em publicações internacionais, em função do ano, autoria e periódico/editora

\begin{tabular}{|c|c|c|c|}
\hline Título & Ano & Autoria & Periódico/editora \\
\hline Guidelines for web-based guidance & s.d & $\begin{array}{l}\text { European } \\
\text { Commission }\end{array}$ & ARIADNE \\
\hline Annual review & 1997 & Niles & $\begin{array}{l}\text { The Career Development } \\
\text { Quartely }\end{array}$ \\
\hline $\begin{array}{l}\text { Integrating internet-based distance } \\
\text { guidance with services provided in career } \\
\text { centers }\end{array}$ & 1999 & Sampson & $\begin{array}{l}\text { The Career Development } \\
\text { Quartely }\end{array}$ \\
\hline $\begin{array}{l}\text { Using the internet on career planning and } \\
\text { assessment }\end{array}$ & 2000 & $\begin{array}{l}\text { Reile e Harris- } \\
\text { Bowlsbey }\end{array}$ & Journal of Career Assessment \\
\hline Mining the internet for career information & 2000 & $\begin{array}{l}\text { Robinson, Meyer } \\
\text { Prince, McLean e } \\
\text { Low }\end{array}$ & Journal of Career Assessment \\
\hline $\begin{array}{l}\text { Ethical issues in the design and use of } \\
\text { internet-based career assessment }\end{array}$ & 2000 & Sampson e Lumsden & Journal of Career Assessment \\
\hline Psicologia da orientação & 2001 & Guichard e Huteau & Editora Piaget \\
\hline $\begin{array}{l}\text { Quality and ethics in internet-based } \\
\text { guidance }\end{array}$ & 2002 & Sampson & $\begin{array}{l}\text { Internacional Journal for } \\
\text { Educational and Vocational } \\
\text { Guidance }\end{array}$ \\
\hline Editorial & 2002 & Esbroeck & $\begin{array}{l}\text { Internacional Journal for } \\
\text { Educational and Vocational } \\
\text { Guidance }\end{array}$ \\
\hline $\begin{array}{l}\text { Delivery of career development information } \\
\text { in the context of information computer } \\
\text { technology }\end{array}$ & 2002 & $\begin{array}{l}\text { Savard, Gingras e } \\
\text { Turcotte }\end{array}$ & $\begin{array}{l}\text { International Journal for } \\
\text { Educational and Vocational } \\
\text { Guidance }\end{array}$ \\
\hline
\end{tabular}

continua 
continuação

\begin{tabular}{|c|c|c|c|}
\hline Título & Ano & Autoria & Periódico/editora \\
\hline The role of information and communication & 2002 & Watts & International Journal for \\
\hline Technologies in integraded career & & & Educational and Vocational \\
\hline information and guidance systems & & & Guidance \\
\hline $\begin{array}{l}\text { Career development interventions in the } 21 \\
\text { st Century }\end{array}$ & 2005 & $\begin{array}{l}\text { Niles e Harris- } \\
\text { Bowlsbey }\end{array}$ & Pearson \\
\hline The internationalization of Educational and & 2005 & Savickas, Esbroeck e & The Career Development \\
\hline Vocational Guidance & & Herr & Quartely \\
\hline
\end{tabular}

Tabela 2

Distribuição dos estudos em publicações nacionais, em função do ano, autoria e Periódico/editora

\begin{tabular}{|c|c|c|c|}
\hline Título & Ano & Autoria & Periódico/editora \\
\hline $\begin{array}{l}\text { Uma nova proposta em orientação } \\
\text { profissional }\end{array}$ & 1988 & Ferretti & Cortez \\
\hline $\begin{array}{l}\text { A internet como ferramenta para o } \\
\text { desenvolvimento da identidade profissional }\end{array}$ & 2003 & Terêncio e Soares & Psicologia em Estudo \\
\hline $\begin{array}{l}\text { Avaliação da informação profissional num } \\
\text { processo de orientação profissional via } \\
\text { internet }\end{array}$ & 2004 & Nogueira & $\begin{array}{l}\text { Dissertação de Mestrado } \\
\text { Universidade Federal de } \\
\text { Santa Catarina }\end{array}$ \\
\hline $\begin{array}{l}\text { A orientação profissional no contexto da } \\
\text { educação e trabalho }\end{array}$ & 2004 & $\begin{array}{l}\text { Melo-Silva, Lassance e } \\
\text { Soares }\end{array}$ & $\begin{array}{l}\text { Revista Brasileira de } \\
\text { Orientação Profissional }\end{array}$ \\
\hline Programa de informação profissional & 2005 & Lobo & $\begin{array}{l}\text { Dissertação de Mestrado } \\
\text { PUC }\end{array}$ \\
\hline Orientação profissional online & 2005 & Spaccaquerche & $\begin{array}{l}\text { Revista Brasileira de } \\
\text { Orientação Profissional }\end{array}$ \\
\hline $\begin{array}{l}\text { Exploração vocacional e informação } \\
\text { profissional percebida em estudantes } \\
\text { carentes }\end{array}$ & 2005 & $\begin{array}{l}\text { Sparta, Bardagi e } \\
\text { Andrade }\end{array}$ & Aletheia \\
\hline PIP - Programa de Informação Profissional & 2005 & Médico & Casa do Psicólogo \\
\hline $\begin{array}{l}\text { A autoeficácia na utilização da internet para a } \\
\text { pesquisa de informação escolar e profissional }\end{array}$ & 2008 & Inácio e Gamboa & $\begin{array}{l}\text { Revista Brasileira de } \\
\text { Orientacão Profissional }\end{array}$ \\
\hline
\end{tabular}

Após o levantamento, procedeu-se à organização dos dados em três conjuntos, com base nos modelos gerais de Robinson, Meyer, Prince, McLean e Low (2000), a saber: (a) informação de carreira realizada por meio de materiais impressos, (b) programas e sistemas de informação mediados por computador e (c) a sites. Os resultados são apresentados, analisados e discutidos a partir das vantagens e das desvantagens dos referidos modelos, tanto na qualidade da informação sobre as carreiras quanto do mecanismo de acesso às informações, com ênfase maior para o terceiro modelo. Em uma quarta subseção são discutidos alguns estudos brasileiros. 


\section{A informação profissional realizada por meio de material impresso}

O primeiro modelo, mais antigo e mais comum, consiste na informação profissional realizada por meio de material impresso. As informações podem ser obtidas em bibliotecas, livrarias e bancas de revista (guias, livros, artigos, reportagens), banco de dados do governo e associações profissionais. As vantagens nesse modelo consistem nas consultas a documentos, que podem ser utilizados em entrevistas com profissionais, possibilitando a assistência humana. As pessoas se beneficiam do vínculo com os demais, pois são observados benefícios nas trocas entre as pessoas sobre suas experiências. Ainda que haja disponibilização de recursos informativos em formato de impressos, a intervenção humana é imprescindível. Por outro lado, há desvantagens como, por exemplo, a pessoa precisar se locomover até o local onde estão os recursos, a informação poder se tornar obsoleta e os recursos materiais correrem o risco de ser extraviados.

Quanto à informação disponível na mídia escrita, ainda no século passado e antes do advento da internet, no Brasil, Ferretti (1988) realizou um levantamento das publicações (catálogo de cursos de nível médio e superior, cursos e profissões, manual do candidato, folhetos) que tratavam da informação profissional para o adolescente. Uma das características dos materiais analisados, naquela época, consistia na forma concisa de apresentação dos dados, que muitas vezes representa uma seleção do conteúdo e da qualidade da informação que deixam a desejar.Outras características são a objetividade, a simplicidade e a neutralidade de que o dado vem revestido, não incluindo questões e reflexões para promover uma análise crítica. Esse levantamento permanece bastante atual quando se observam os guias e catálogos impressos, na contemporaneidade, que em sua maioria pouco mudaram das características apontadas por Ferretti (1988)."Ao veicular informação da forma como o fazem, os textos, na verdade, não deixam de emitir juízos de valor" (Ferretti, 1988, p. 70). Por sua vez, para Guichard \& Huteau (2001) neste século e no contexto europeu -, a informação, ao ir além de uma simples descrição das formações e das profissões, veicula visões da sociedade que darão determinado sentido ao desenvolvimento profissional, o que nem sempre é explicitado nos textos. Reafirma-se que a Orientação de Carreira, para ser eficaz, deve ter como objetivo básico o fornecimento de informações fidedignas sobre profissões a fim de estimular a reflexão e o pensamento crítico sobre o seu exercício. Fornecer informações impressas continua sendo útil nas intervenções e, sobretudo, em feiras de profissões. Quanto à qualidade desse tipo de material o debate continua aberto. 


\section{Informações realizadas por meio de Programas e Sistemas mediados por Computador}

O segundo modelo consiste em informações através do Sistema CACG (Computer-Assisted Career Guidance Systems). São sistemas ou programas computadorizados de auxílio da orientação de carreira, utilizados em países desenvolvidos disponíveis em bibliotecas, cujas fontes podem ser do governo e/ou de recursos independentes. Os programas podem abarcar várias possibilidades de utilização dependendo do seu propósito. Esses programas podem administrar testes ou inventários, proporcionar aprendizagem para tomada de decisão vocacional, fornecer informações gerais sobre as profissões, locais de trabalho, mercado, universidades, desenvolver planos de ação, elaboração de currículo, selecionar entrevistas de emprego e sugerir estratégias de investimento no próprio negócio. Como vantagens destaca-se que a pessoa pode localizar várias ocupações diferentes em um mesmo local e a utilização de cores, gráficos e outros recursos. Nesse modelo, o mecanismo de acesso é direto e as vantagens são: pode ser autodirigido, há anonimato, há algumas interfaces entre as avaliações e as informações, o resultado é instantâneo, a utilização pode ser armazenada e os programas são específicos para as etapas do desenvolvimento e do ano escolar. Como desvantagens são apontados: a locomoção até o local do serviço, rigidez, validade, não serem consideradas as questões multiculturais e a limitação da habilidade do usuário na utilização desse método.

Segundo Watts (2002), a evolução da utilização das Tecnologias de Informação e Comunicação (TICs) no campo da Informação de Carreira e da Orientação Profissional pode ser dividida em quatro fases. Na primeira fase, de construção, que data de meados da década de 1960 e início de 1970 , foram desenvolvidos os primeiros sistemas em Orientação Profissional e de Carreira demonstrando o potencial da TIC, em países desenvolvidos. Entretanto, o custo e a interação com os usuários eram restritos. Naquela época ocorreram as primeiras aplicações da informática na avaliação psicológica, sendo a utilização basicamente para a correção de testes e de provas psicométricas que realizavam análises estatísticas longas e sofisticadas. A segunda fase, que aconteceu na década de 1980 até meados de 1990, por meio da utilização do computador tornou-se mais viável economicamente e desdobrou-se no desenvolvimento de software em versões de utilização facilitadas e com mais recursos. Consequentemente houve um crescimento no número de sistemas de informação para uso nesse domínio nos países desenvolvidos. A terceira fase ocorreu no final dos anos 1990, com o advento da internet. As pessoas passaram a acessar a rede não apenas por meio de seu computador pessoal, mas também da televisão e dos aparelhos celulares. Essa temática será retomada 
na próxima subseção. Para Watts (2002), no decorrer das quatro fases, foram sendo adicionadas vantagens como o crescimento na facilidade dos acessos à Orientação e Informação Profissional por meio das TICs acessíveis a várias pessoas e de qualquer lugar.

Os programas informáticos de Orientação e Informação Profissional são de vários tipos; a seguir alguns são apresentados. O primeiro deles são os sistemas ou instrumentos de avaliação, no qual o próprio sistema administra um ou mais testes ou inventários de interesse, de habilidades e de características de personalidade, que em seguida são interpretados e indicam as possíveis profissões. Outro tipo de sistema é o que fornece informações sobre a profissão, locais de trabalho, mercado, universidades disponíveis; são especializados em banco de dados e pesquisas.

E o último tipo são os sistemas analógicos que através de sistemas de aprendizagem auxiliam o usuário a efetuar a decisão profissional. Eles auxiliam a desenvolver planos de ação, preparar currículo, preparar e selecionar entrevistas, selecionar oportunidades ou a investir no próprio negócio, contendo uma grande variedade de Informações Profissionais (Guichard \& Huteau, 2001; Watts, 2002; Niles \& Harris-Bowlsbey, 2005).

Segundo Niles e Harris-Bowlsbey (2005), os primeiros teóricos (Katz, Super e Tiedeman) a desenvolver esses sistemas para computador acreditavam que os mesmos poderiam ser uma forma de ensinar as suas teorias diretamente aos usuários, internalizando o aprendizado. Esses primeiros sistemas eram baseados em modelos teóricos. E um exemplo dessa época é o System for Interactive Guidance Information (SIGI) desenvolvido por Katz em 1963. Depois disso, Super desenvolveu o Education and Career Exploration System (ECES). Por sua vez, David Tiedeman em 1963 desenvolveu o Information System for Vocational Decisions (ISVD), com o objetivo de ensinar ao usuário a transpor os seis degraus na escolha de carreira. O primeiro degrau consiste na necessidade de reconhecer que existe um problema e que é preciso informação; o segundo consiste em selecionar a informação que atende às necessidades; o terceiro visa à decisão de como usar a informação; o quarto em utilizar as pesquisas das informações; o quinto em avaliar se as necessidades foram sanadas; e o sexto em procurar ajuda ou outros recursos necessários até que o problema esteja resolvido. A grande sofisticação desse programa não se tornou operacional na época.

Entre os referenciais teórico-metodológicos no domínio da Orientação Vocacional, Profissional ou de Carreira, a perspectiva mais antiga é a psicotécnica, sendo os sistemas analógicos parte dessa prática. Algumas das suas proposições consideram que os indivíduos podem ser descritos por aptidões estáveis, as profissões podem ser descritas pelas suas exigências estáveis, os indivíduos são capazes de tomar decisões racionais. Esse modelo denominado teoria traço-fator, apresentado pela pri- 
meira vez por Frank Parsons em 1909, visava emparelhar o perfil do indivíduo com o perfil da profissão (Guichard \& Huteau, 2001).Com base nesse paradigma, foi desenvolvido no Canadá o protótipo utilizado, em uma perspectiva educativa, do Computerized Heuristic Occupational Information and Career Exploration System (CHOICES). A partir dessa versão outros foram criados em função do público-alvo. Mais recentemente a análise das relações entre a variabilidade individual e as condutas de orientação foram renovadas pela contribuição da corrente interacionista, no campo da psicologia da personalidade e da psicologia cognitiva, que consideram as características individuais e suas variações (Guichard \& Huteau, 2001). Essas últimas proposições começam a se enquadrar mais no mundo atual, em que se fala em competências a serem desenvolvidas ao longo da vida.

Os programas informáticos mais ambiciosos são os sistemas de aprendizagem que pretendem alcançar quatro objetivos: (a) promover o autoconhecimento, (b) conhecer o mundo do trabalho, (c) adquirir competências para a tomada de decisão e (d) transferir as competências para o mundo escolar e do trabalho. Ao se avaliar os efeitos desses programas, nos EUA, a satisfação dos usuários ficou em torno de $90 \%$. Entretanto, esses programas informáticos evoluíram pouco nos últimos anos. A primeira razão é de ordem teórica, pelo fato de que as ideias sobre o processo de elaboração das intenções de futuro não se alteraram significativamente e por isso não há sentido em que os programas se alterem. E a outra razão é de ordem econômica, pois a construção e a manutenção demandam grandes investimentos (Guichard \& Huteau, 2001).

Desde os anos 1960 até hoje a tecnologia vem trazendo avanços em relação à assistência a pessoas em processo de planejamento de carreira. Porém, a utilização de programas incorre na mesma desvantagem do material impresso, a informação pode se tornar obsoleta.

\section{Informação obtida por meio da internet}

Nesse terceiro modelo a informação está localizada na internet, em diferentes web sites, e as fontes podem ser de governos, associações profissionais e, ainda, publicações educacionais e de universidades. As vantagens são várias, pois há muitos sites com múltiplos recursos, é possível procurar informações nas mais variadas ocupações, o recurso é prioritariamente visual, há flexibilidade, informações rápidas e relativamente atualizadas.

A principal desvantagem da busca de informação pela internet é que muitas vezes o adolescente não tem a orientação de um profissional para ajudar a decifrar as informações. Sem a intervenção humana direta, o acesso é desigual, pode não ser adequado para as condições emocio- 
nais. Outra preocupação é:qual Informação Profissional é confiável? Esse modelo requer manutenção constante. E nem sempre fica clara a fonte da informação disponibilizada no site. A variedade, a validade e a qualidade das informações podem dificultar uma intervenção eficaz (Robinson et al., 2000).

Para Reile e Harris-Bowlsbey (2000), quando os orientandos utilizam esses instrumentos na internet alguns passos devem ser seguidos pelo orientador profissional:(a) explicar o propósito e as expectativas de se utilizar esse instrumento; (b) explicar como utilizar e qual a melhor direção e (c) pedir para que o orientando traga impressos os resultados obtidos com a sua pesquisa, assim o orientador terá a oportunidade de ajudá-lo a usufruir melhor de seus dados.

Desde a criação desses programas informáticos muito se especulou a respeito cogitando que os mesmos iriam substituir os orientadores profissionais. No entanto, o que se tem observado é que "com os sistemas atuais, há um resultado que aparece adquirido: a interação com os programas informáticos não reduz a procura de contatos pessoais com um orientador, bem pelo contrário, aumenta-a" (Guichard \& Huteau, 2001, p. 310). Como sugerem as pesquisas, para alcançar melhores resultados propõe-se a utilização conjunta da internet ou de sistemas informáticos com os métodos tradicionais a fim de otimizar o desempenho do orientador profissional, em vez de colocar as duas estratégias de intervenção em situação competitiva. Os recursos informatizados podem ser integrados às práticas dos orientadores (Guichard \& Huteau, 2001; Niles \& HarrisBowlsbey, 2005; Reile \& Harris-Bowlsbey, 2000).

Segundo Niles e Harris-Bowlsbey (2005), existem pelo menos três razões que impossibilitam a Orientação Profissional pelo computador sem a presença do orientador. A primeira razão é que para ajudar pessoas na tarefa de escolha da profissão muitas variáveis devem ser levadas em consideração, o que não é possível apenas com os programas computacionais. A segunda razão, as pessoas têm diferentes estilos de aprendizagem e personalidade, demandando processos diferentes para atender a cada necessidade. E por último, as pesquisas vêm mostrando que o meIhor caminho para o planejamento de carreira é a combinação do serviço humano com o mediado por computador.

Contudo,é inevitável que muitas pessoas utilizem os instrumentos disponíveis na internet sem a preparação ou intervenção de orientador profissional, podendo muitas vezes ter bons resultados na utilização dos mesmos no processo de escolha da sua profissão. Nesses casos algumas considerações são importantes para aumentar as oportunidades de um bom aproveitamento, a saber:a natureza do instrumento (elaborado para autoajuda), a qualidade do instrumento para fazer as interpretações e, finalmente, a maturidade profissional do cliente (Reile \& Harris-Bowlsbey, 2000). Por sua vez, Niles e Harris-Bowlsbey (2005) acrescentam que o 
orientador deverá determinar a prontidão da pessoa para receber a informação por meio do computador e aplicá-la efetivamente; expandir na interpretação de teste e inventários para poder informar ao cliente se o mesmo está tomando a decisão apropriada; identificar valores pessoais que reduzirão as opções fornecidas pelo computador, promover motivação e suporte emocional para manter o trabalho de planejamento de carreira e, finalmente, sugerir alternativas criativas que não estão disponíveis no computador.E, para isso, o orientador precisa desenvolver algumas competências, como: conhecer os vários sistemas computadorizados e web sites, ter capacidade de diagnosticar as necessidades do orientando, motivar no percurso da orientação, auxiliar no processamento das informações e ter capacidade de direcionar um plano de ação que possa ser bem-sucedido. Essas competências poderão ser aplicadas em combinação com vários modelos diferentes de orientação profissional em trabalhos individuais, em grupos de orientação profissional ou em salas de aula (Niles \& Harris-Bowlsbey, 2005).

Os orientandos, por sua vez, têm um papel importante no processo, terão que completar as colocações ou sugestões do orientador, pensando e refletindo sobre seus interesses, engajando-se nas atividades propostas. É fundamental a implicação do jovem no processo de busca de Informação Profissional, principalmente por ser a busca de informação no banco de dados de acesso muito rápido. No entanto, existe o perigo da informação ser tratada superficialmente porque o sujeito pode considerar,erradamente, que deve acompanhar o ritmo do computador e não processar internamente os conteúdos. Por outro lado, para Guichard e Huteau (2001) a busca de informações pela internet dá a possibilidade de criar ferramentas que apresentam duas propriedades pedagógicas:a interação com a informação e a possibilidade de caminhos individualizados na procura da informação.

A possibilidade da utilização de novos meios tecnológicos, como: telefone, web site, e-mail, links, chats com facilidades em entrevistas face a face abrem novas oportunidades de Informação e Orientação Profissional. Isso significa que as pessoas podem acessar ajuda da forma que seja conveniente e confortável para cada um. Para Watts (2002), todos esses meios tecnológicos poderiam ser considerados não somente como serviços alternativos, mas como uma ampla, flexível e harmoniosa rede de serviços que enriquecem o aprendizado de caminhos disponíveis aos indivíduos.

Segundo o Guidelines for web-based guidance (European Commission, s.d.), a internet reúne várias outras vantagens em sua utilização, principalmente por ser um instrumento poderoso de se obter informações, ser também um meio democrático, igualitário, de acesso livre e fácil, de material farto,em comparação à antiga mídia, e de informações rapidamente atualizadas. Entretanto, a desvantagem seria a dificuldade de controlar as informações quanto à qualidade das mesmas. 
Os usuários dos sites deveriam desenvolver julgamentos, ou critérios para serem analisados ao acessar as informações. O primeiro critério é verificar a atualidade do site, com que periodicidade ele é revisado. Além disso, as informações fornecidas devem conter as fontes, os organizadores do web site devem fornecer endereço e/ou outro contato, considerar as variedades socioculturais mundiais, estar atento ao propósito ou finalidade do conteúdo, verificar a presença de argumentos razoáveis, justificados, balanceados com pontos de vista alternativos. Para tanto, o usuário deve desenvolver habilidade cognitiva para lidar com a informação encontrada nas webs, para selecionar, organizar e sintetizar informações qualificadas.

O aumento da demanda por esse tipo de serviço mostra os aspectos positivos, em que o usuário pode determinar a hora da procura, os caminhos que prefere percorrer, o limite de tempo desejado, além de ser mais uma opção para aqueles que se sentem desconfortáveis com as orientações realizadas pessoalmente (Sampson \& Lumsden, 2000). A maior desvantagem da utilização apenas da internet na Orientação Profissional é a redução do contato pessoal entre os estudantes e os orientadores, como apontam Reile e Harris-Bowlsbey (2000).

As novas tecnologias oferecem novas possibilidades de Orientação Profissional e de Carreira de maneira mais eficiente e fácil, mas com certeza funciona diferentemente dos moldes tradicionais. A tarefa do orientador é promover a escolha profissional de modo autônomo. Quando as pessoas podem ter esse apoio na web, analisando suas qualidades e características, relacionando-as com as informações acerca das possibilidades de educação, o trabalho do orientador adquire características pedagógicas (European Commission, s.d.). A proposta de intervenção nesse domínio se amplia ao valorizar a importância da ação educativa com os adolescentes em processo de escolha profissional, no sentido de formar um homem integrado com seu mundo, promovendo uma reflexão que enriquece a si e ao meio.

O desafio da nova tecnologia não está em fazer as mesmas coisas de uma nova maneira, mas em desenvolver uma prática à luz das novas possibilidades. Para tanto, teorias terão que surgir considerando os novos contextos e oferecer perspectivas diversificadas. Um dos desafios que merece discussão é sobre questões éticas do atendimento de Orientação Profissional na web. Um dos aspectos mais importantes refere-se aos conteúdos confidenciais, a todas as informações sobre o usuário:quem é responsável por esses dados, qual é a proteção contra intrusos para a manutenção da integridade dos usuários? Além de outros aspectos, como os referentes à linguagem utilizada, o respeito à diferença cultural e a acessibilidade dos sites a todas as pessoas.

Segundo Sampson e Lumsden (2000), alguns cuidados devem ser tomados no uso da internet como veículo de consulta. Um deles consiste 
em verificar a boa qualidade, além de conter de forma clara as referências (fontes) e datas dos instrumentos e demais informações. Algumas questões éticas, também, foram apontadas pelos autores, como: na administração de testes pela internet é importante um cuidado com a validade dos mesmos para serem aplicados em condições adversas, uma vez que o controle de padronização fica seriamente comprometido, demandando o desenvolvimento de testes específicos para a utilização pela internet. Outro cuidado, na utilização da internet sem o contato pessoal com o orientador profissional, refere-se às informações sobre as condições socioeconômicas do orientando, como de outros dados importantes que podem influenciar de alguma forma na tomada de decisão de carreira. Outra questão levantada quanto ao uso da internet é o fato de não ser equitativo, uma vez que as pessoas com limitações financeiras têm maiores dificuldades de acesso. Os autores, ainda, destacam a questão do sigilo e da privacidade das informações fornecidas pelos orientandos serem ainda questionáveis; é importante que o usuário do siteesteja ciente dos riscos inerentes a esse tipo de serviço (Sampson \& Lumsden, 2000).

O fato da qualidade das webs variarem maciçamente remete a como elaborar controles sem interferir na liberdade de comunicação. Outra discussão importante alude a quem ficaria com essa função: profissionais, usuários ou governo? Uma solução, segundo Watts (2002), seria a transparência, ser honesto com os usuários e informar que todo o possível será feito para protegê-los. Mas trabalhando por meio da web existem limites e territórios desconhecidos que, ao se deparar com as questões éticas, podem não ser identificados.

Uma reflexão proposta por Sampson (2002) adverte que é fácil concluir que a responsabilidade em manter a qualidade e a ética nos serviços oferecidos e disponibilizados na web seja dos seus mentores e mantenedores. Entretanto, o autor sugere que uma análise mais cuidadosa revela que essa responsabilidade é função de um sistema de múltiplos participantes, como:mentores, mantenedores, usuários, políticos, pesquisadores e avaliadores.Mesmo os sites subsidiados ou financiados por órgãos públicos não seguem um padrão de qualidade e objetivos claros (Esbroeck, 2002; Niles \& Harris-Bowlsbey, 2005; Savickas, Esbroeck, \& Herr, 2005;Watts, 2002). Essa deveria ser também uma preocupação dos orientadores profissionais no Brasil, no sentido de desenvolver pesquisas na área e de aplicálas na prática da utilização da internet no dia a dia dos adolescentes.

Além de todas essas questões mencionadas, os estudos e revisões de Savard, Gingras, \& Turcotte (2002) mostram que o cliente está experimentando dificuldade em localizar informações relevantes e em utilizálas efetivamente no processo de escolha profissional. Para resolver essa dificuldade uma solução é integrar a utilização de programas de Orientação Profissional virtuais com os serviços presenciais como os oferecidos nos Centros de Orientação Profissional, como aponta Sampson (1999). 
As TICs oferecem aos clientes engajados, no processo de busca de informação, alternativas para a atividade exploratória. Sabe-se que a autoeficácia na internet para a pesquisa de informação escolar e profissional prediz a atividade exploratória, como destacam Inácio e Gamboa (2008) no contexto português. Entretanto, é essencial, como sugere Savard et al. (2002), que esse recurso seja utilizado como parte de um suporte que possa orientar o cliente a utilizar um bom serviço da rede. Esse tipo de suporte só poderá ser definido a partir das características e circunstâncias únicas de cada cliente e dos recursos humanos e técnicos envolvidos no processo.

Tendo em vista que a internet é um recurso moderno, popular e utilizado cada vez mais por muitas pessoas, sobretudo pelos adolescentes, considera-se útil essa ferramenta, preferencialmente associada à intervenção, em processo de orientação profissional e de carreira presencial, como apontam os dados dessa revisão.

\section{Informação profissional no Brasil:implicações para práticas presenciais ou mediadas por computador}

Algumas tentativas foram realizadas, no Brasil, no século passado, com o intuito de introduzir na grade curricular das escolas uma disciplina sobre Informação Profissional. Um exemplo consistiu na elaboração de uma nova disciplina para o Ensino Médio, denominada Programa de Informação Profissional (PIP), por meio da Secretaria da Educação do Estado de São Paulo (Lei 5.692/71 de Diretrizes e Bases). A proposta de atividade curricular nas escolas públicas do Estado de São Paulo era promover a informação e a orientação profissional, que facilitariam o conhecimento do mercado para a escolha da profissão. A proposta vigorou por cinco anos, e acabou extinta por falta de preparo das escolas para realizar a disciplina apropriadamente (Lobo, 2005).

Ainda assim, a Informação Profissional tem sido desenvolvida como uma etapa do processo de escolha profissional, em procedimentos formais ou informais de orientação de carreira. Medico (2005) sugere o início da orientação nas primeiras séries da escolarização, a desenvolver-se como um processo contínuo, paralelo ao desenvolvimento geral do indivíduo. Essa estratégia de intervenção na literatura internacional é denominada de Educação para a Carreira, incluindo atividades de exploração realizadas por meio da informação impressa ou on-line. Seja qual for o modelo de intervenção é importante facilitar a exploração vocacional para a escolha de carreira. Nesse sentido, Sparta et al. (2005) apontam a carência de trabalhos de Orientação e Informação Profissional com pessoas que buscam o acesso à universidade, mas não possuem uma rede de apoio à construção de um projeto profissional. 
No que se refere à legislação que regulamenta a utilização da internet na área específica da Psicologia, o Conselho Federal de Psicologia por meio da Resolução n 003/2000 de 25 de setembro de 2000 (http:/ /pol.org.br/legislacao/pdf/resolucao2000_3.pdf), em seu Art.5', reconhece os serviços psicológicos mediados por computador, desde que não psicoterapêuticos, tais como orientação psicológica, desde que pontuais e informativos, orientação profissional, dentre outros, como a utilização de testes informatizados devidamente validados, utilização de softwares informativos e educativos com resposta automatizada e outros, desde que não firam o disposto no Código de Ética Profissional do Psicólogo.

No Brasil vem crescendo gradativamente esse tipo de oferta, ainda que seja questionável quem tem acesso a esses recursos. Nas informações profissionais virtuais várias são as modalidades. No site www.sitedebusca.com.br foram selecionados 45 sítios diferentes de Orientação e Informação Profissional. Outro sítio bastante amplo é o www.vestibular1.com.br, que além de Informação Profissional oferece testes para a escolha da profissão e serviços diversos de auxílio ao vestibulando, disponibilizando outros 43 sites de Informação Profissional. Nesse panorama não estão contabilizados os sítios das universidades.

Os diversos programas de Informação Profissional, no Brasil, são oferecidos pela internet em sintonia com o avanço das novas tecnologias. São sítios com informações sobre profissões, vestibulares e cursos (Spacaquerche, 2005). Os serviços on-line de qualidade, em geral, estão vinculados a projetos de pesquisas e a Programas de Pós-graduação (Melo-Silva et al., 2004). Um deles é oferecido pelo Laboratório de Informação e Orientação Profissional (LIOP) da Universidade Federal de Santa Catarina (UFSC). Terêncio e Soares (2003), em um estudo que avalia o programa, salientam que apesar de serem otimistas quanto ao uso da internet em Orientação Profissional, consideram que a mesma não substitui a qualidade da intervenção presencial. Outro estudo desenvolvido por Spacaquerche (2005) analisa a experiência de um programa de Orientação Profissional mediado por computador em uma parceria da Pontifícia Universidade Católica de São Paulo (PUC-SP) com o Banco do Brasil, visando ao atendimento a adolescentes trabalhadores. Outra instituição, a Universidade de Brasília (Siebiger, s.d.), apresenta uma proposta de Orientação e Informação Profissional oferecida via internet, vinculado à Associação Brasileira de Educação a Distância (ABEaD), e propõe a constituição de um site com grupo de discussão, banco de pesquisas, entre outras atividades. Esses são alguns dos exemplos de uma ampla gama de opções disponíveis ao adolescente, no contexto brasileiro. Necessário se faz sistematizar tais intervenções e avaliar os resultados.

Nessa direção, Nogueira (2004) avalia a Informação Profissional num processo de Orientação Profissional via internet, verificando seus limites 
e alcances. A autora concluiu que os resultados mostraram que a Informação Profissional no processo de Orientação Profissional via internet pôde auxiliar na escolha da profissão dos participantes.

Com relação aos jovens brasileiros em situação de escolha da carreira, sabe-se que muitos deles estão habilitados para lidar com o mundo digital.Porém, o questionamento é se eles estão utilizando a internet como recurso para obter informações sobre as carreiras e as profissões universitárias de forma a auxiliar no amadurecimento tendo em vista o processo de tomada de decisão acerca da carreira profissional.

\section{Considerações finais}

Os resultados mostram que a Informação Profissional mediada por computador, em países desenvolvidos, é frequente, desdobrando-se em estudos e sistematizações dos serviços. O que difere do contexto brasileiro, que apresenta poucas experiências sistematizadas sobre o uso de programas mediados por computador.

Conclui-se que as tecnologias da informação e comunicação representam uma nova oportunidade de crescimento e desenvolvimento para a Orientação Profissional, com desafios e limites a serem traçados em um campo que não para de evoluir. Muitos aspectos dessa questão deverão ser pensados à procura de soluções abrangentes tanto no que se refere à informação quanto à orientação profissional tanto presencial quanto mediada por computador. Muito ainda há que se caminhar no Brasil no sentido de melhorar a qualidade, acesso, criação e utilização de sistemas com tecnologia nacional apropriados às diferentes regiões do país. No sistema educacional contemporâneo inexiste legislação que contemple a Informação e a Orientação Profissional. Em diversas câmaras municipais e estaduais tramitam projetos de lei sugerindo a obrigatoriedade da "Orientação Vocacional" nas escolas. A maioria deles com propostas equivocadas (Silva, 2010), uma vez que fundamentados em modelos de orientação profissional considerados ultrapassados e não abrangentes para o sistema educativo. A Constituição Brasileira (Brasil, 1988) e a Lei de Diretrizes e Bases da educação nacional (Brasil, 1996) preconizam a preparação para o trabalho, porém o que tem sido oferecido é pouco e inacessível à maioria da população.

Por fim, este estudo evidenciou a presença da informação profissional, com seus limites e possibilidades, em países desenvolvidos. Por outro lado, mostrou poucos estudos de sistematização de dados ou de avaliação de programas presenciais ou mediados por computador na realidade brasileira. Investigações são necessárias sobre: (1) a oferta de serviços, (2) a qualificação e as competências dos profissionais da orientação e (3) as políticas públicas de acesso à informação e orientação 
profissional. E, sobretudo, de acesso às Tecnologias de Informação e Comunicação, janelas de acesso ao conhecimento necessário para a inserção no mundo do trabalho e para o exercício pleno da cidadania.

\title{
Career information and career guidance: a literature revision
}

\begin{abstract}
Career Information, which is one of the constituents of the career guidance process, aims at supplying data from the occupational world in order to help people make their career decision. This study aims to systematize and analyze the production of knowledge about career information based on a literature review. The data was organized into three categories as based on Robinson and coll.: (1) printed resources; (2) information program and systems; and (3) internet sites. The results showed that the new Information and Communication Technologies (ICT's) together with traditional strategies constitute a way of developing Career Information in the context of career guidance, pose challenges and limits to be faced in an ever evolving field. The study highlights the role of Professional Information, with its limitations and possibilities in the Brazilian context as well as in the developed countries.
\end{abstract}

Keywords: Occupational guidance. Vocational guidance. Career guidance. Career information. Information systems.

\section{Information professionnelle et orientation professionelle: une révision littéraire}

Résumé: L'Information Professionnelle, l'un des composants du processus d'Orientation de Carrière, dont l'objet est de révéler les données réelles du monde du travail de manière à aider les personnes dans le processus de prise de decisions. Cette étude vise à systematiser et analyser la production des connaissances sur le thème de l'Information Professionnelle basée sur la révision littéraire. Les données ont été organisées en trois catégories, selon les bases de Robinson et ses collaborateurs: (1) des modèles de ressources imprimées, (2) des logiciels et (3) sites sur internet. Les nouvelles Technologies de l'Information et de la Communication (TICs) associées aux stratégies traditionelles représentent de nombreuses oportunités de developpement de l'Information Professionnelle dans le contexte d'Orientation de Carrière, avec des défis et des limites à affronter dans un domaine en constante évolution. L'étude met en évidence le rôle du professionnel de l'information, avec ses limites et les possibilités dans le contexte brésilien, ainsi que les pays développés. 
Mots-clés: Orientation professionnelle. Orientation vocationnelle. Orientation de carrière. Information professionnelle. Système d'information.

\section{Información profesional y orientación para la carrera mediadas por ordenador: una revisión de la bibliografía}

Resumen: La Información Profesional, uno de los componentes del proceso de Orientación Profesional, Vocacional y para la Carrera, busca suministrar datos de la realidad del mundo ocupacional para auxiliar a personas en proceso de toma de decisión. Este estudio pretende sistematizar y analizar la producción del conocimiento sobre el tema Información Profesional basándose en la revisión de la bibliografía. Los datos fueron organizados en tres categorías teniendo como fundamento a Robinson y colaboradores: (1) modelos de recursos impresos, (2) programas y sistemas de información y (3) sitios en la internet. Se concluye que las nuevas Tecnologías de la Información y Comunicación (TICS) aliadas a las estrategias tradicionales representan innumerables oportunidades de desarrollo de la Información Profesional en el contexto de la Orientación para la Carrera, con desafíos y límites a ser enfrentados en un campo que no para de evolucionar. El estudio evidencia el papel de la Información Profesional, con sus límites y posibilidades, en el contexto brasileño como en el de los países desarrollados.

Palabras clave: Orientación profesional. Orientación vocacional. Orientación para la carrera. Información Profesional. Sistemas de información.

\section{Referências}

Bohoslavsky, R. (1991). Orientação vocacional: a estratégia clínica. São Paulo: Martins Fontes.

Brasil. (1996). Lei no 9.394, de 20 de dezembro de 1996. Diretrizes e Bases da educação Nacional. Presidência da República, Casa Civil, Subchefia para Assuntos Jurídicos, Brasília, DF. Recuperado em 01 de julho de 2009, de http:// wwww.camara.gov.br/internet/InfDoc/novoconteudo/legislaçao/republica/ Leis1996v CLXXXVIIIn12tomo1p678/parte-16,pdf 
Brasil. Ministério do Trabalho. Secretaria de Mão-de-Obra. (1981). Terminologia da formação profissional no sistema nacional de formação de mão-de-obra. Brasília, DF. Autor.

Brasil. (1988). Constituição da República Federativa do Brasil.Recuperado em 01 de julho de 2009, de http://www.www.al.ma.gov.br/arquivos/CON1988.pdf

Brown, D. (2003). Career information, career counseling, and career development. Chapel Hill:Pearson Education.

Esbroeck, R. V. (2002). Editorial. Internacional Journal for Educational and Vocational Guidance, 2,137-138.

European Commission. Guidelines for web-based guidance. (n.d.). Ariadne. Recuperado em 18 de abril de 2007, de http://www.ariadneproject.org

Ferretti, C. J. (1988). Uma nova proposta em orientação profissional. São Paulo: Cortez.

Guichard, J., \& Huteau, M. (2001). Psicologia da orientação.Lisboa:Instituto Piaget.

Inácio, P., \& Gamboa, V. (2008). A auto-eficácia na utilização da internet para a pesquisa de informação escolar e profissional. Revista Brasileira de Orientação Profissional, 9(1), 13-28.

Lobo, S.M. A. (2005). Programa de informação profissional:uma atividade de orientação profissional na escola.Dissertação de Mestrado,Pontifícia Universidade Católica de São Paulo, São Paulo.

Medico, M. D. (2005). PIP - Programa de Informação Profissional.São Paulo:Casa do Psicólogo.

Melo-Silva, L. L. (2011). Intervenção e Avaliação em Orientação Profissional e de Carreira. In M. A. Ribeiro \& L. L.Melo-Silva (Orgs.), Compêndio de orientação profissional e de carreira: Enfoques contemporâneos e modelos de intervenção(Vol.2).São Paulo:Vetor.

Melo-Silva, L. L., Lassance, M. C.P., \& Soares, D. H.P. (2004). A orientação profissional no contexto da educação e trabalho. Revista Brasileira de Orientação Profissional, 5(2), 31-52.

Niles, S.G. (1997). Annual review:Practice and research in career counseling and development. The Career Development Quartely, 46,115-41.

Niles, S. G., \& Harris-Bowlsbey, J. (2005). Career development interventions in the 21 st Century.Ohio:Pearson. 
Nogueira, R.S.F.R. (2004). Avaliação da informação profissional num processo de O. P. via Internet. Dissertação de Mestrado, Universidade Federal de Santa Catarina, Florianópolis.

Reile,D.M., \& Harris-Bowlsbey, J. (2000). Using the internet in career planning and assessement. Journal of Career Assessment, 8,69-84.

Robinson, N. K., Meyer, D., Prince, J. P., McLean, C., \& Low, R. (2000). Mining the internet for career information: A model approach for college students. Journal of Career Assessment, 8, 37-54.

Sampson, J.P.(1999). Integrating internet-based distance guidance with services provided in career centers. The Career Development Quartely, 47,243-254.

Sampson, J.P. (2002). Quality and ethics in internet-based guidance. Internacional Journal for Educational and Vocational Guidance, 2, 157-171.

Sampson, J. P. Jr., \& Lumsden, J. A. (2000). Ethical issues in the design and use of internet-based career assessment. Journal of Career Assessment, 8, 21-35.

Savard, R., Gingras, M., \& Turcotte, M. (2002). Delivery of career development information in the context of information computer technology. Internacional Journal for Educational and Vocational Guidance, 2,173-191.

Savickas, M. L. (2001). A developmental perspective on vocational behaviour: Career patterns, saliente, and themes. Internacional Journal for Educational and Vocational Guidance, 1,49-57.

Savickas, M. L., Esbroeck, R. V., \& Herr, E. L. (2005). The Internationalization of Educational and Vocational Guidance. The Career Development Quartely, 54, 77-85.

Siebiger, R.H.(n.d.). Orientação e informação profissional via internet:Uma proposta. Universidade de Brasília, s.d.Retirado em 20 fevereiro 2007, de http:// www.abed.org.br

Silva, F. F. (2010). Construção de projetos profissionais e redução da vulnerabilidade social:subsídios par apolíticas públicas de orientação profissional no ensino médio.Tese de Doutorado, Instituto de Psicologia, Universidade de São Paulo, São Paulo.

Spaccaquerche, M.E. (2005). Orientação profissional online:uma experiência em processo. Revista Brasileira de Orientação Profissional, 6(1),63-75.

Sparta, M., Bardagi, M.P., \& Andrade, A. M. J. (2005). Exploração vocacional e informação profissional percebida em estudantes carentes. Aletheia, 22,79-88. 
Spokane,A. R. (2004). Avaliação das intervenções de carreira.In L.M. Leitão (Ed.), Avaliação psicológica em orientação escolar e profissional (pp. 455-473). Coimbra:Quarteto.

Taveira, M.C. (2000). Exploração e desenvolvimento vocacional de jovens. Braga: Lusografe.

Terêncio, M.G., \& Soares, D.H.P.(2003).A internet como ferramenta para o desenvolvimento da identidade profissional. Psicologia em Estudo, 8, 139-145.

Watts, A. G. (2002). The role of information and communication technologies in integrated career information and guidance systems: A policy perspective. Internacional Journal for Educational and Vocational Guidance, 2, 139-155. 
Marystella Carvalho Esbrogeo, Faculdade de Filosofia, Ciências e Letras de Ribeirão Preto, Universidade de São Paulo. Endereço para correspondência: Av. Bandeirantes, 3900, Ribeirão Preto, SP, Brasil.CEP: 14040-901.Endereço eletrônico:marystella@terra. com.br

Lucy Leal Melo-Silva, editora da Revista Brasileira de Orientação Profissional. Departamento de Psicologia e Educação, Faculdade de Filosofia, Ciências e Letras de Ribeirão Preto, Universidade de São Paulo. Endereço para correspondência: Av. Bandeirantes, 3900, Ribeirão Preto, SP, Brasil. CEP: 14040-901. Endereço eletrônico: lucileal@ ffclrp.usp.br 